\title{
"Una realidad que llegó para quedarse": La CTEP y el escenario emergente a partir de la Marcha de San Cayetano (2016)
}

\author{
"A reality that has come to stay": CTEP and the emerging scenario since the \\ March of San Cayetano (2016)
}

Laureano Javier Gonzalez

laureegonzalez@gmail.com

Instituto de Investigaciones en Humanidades y

Ciencias Sociales (UNLP - CONICET). Facultad de

Humanidades y Ciencias de la Educación. Universidad

Nacional de La Plata, Argentina

Recepción: 11 Abril 2020

Aprobación: 07 Julio 2020

Publicación: 01 Septiembre 2021

Cita sugerida: Gonzalez, L. J. (2021). "Una realidad que llegó para quedarse”: La CTEP y el escenario emergente a partir de la Marcha de San Cayetano (2016). Sociohistórica, 48, e146. https://doi.org/10.24215/18521606e146

\begin{abstract}
Resumen: En el siguiente artículo nos proponemos ver cómo a partir de la marcha de San Cayetano por Paz, Pan, Tierra, Techo y Trabajo (2016) se abrió un nuevo escenario social y político para la Central de los Trabajadores de la Economía Popular (CTEP). Aquí destacamos tres aspectos. En primer lugar, la visibilidad que cobró la organización, el sector social que representa y sus demandas. En segundo lugar, el rol de esta movilización en el fortalecimiento de los vínculos entre las diferentes organizaciones de la Economía Popular. Y, en tercer lugar, el acercamiento a otros sectores sociales, principalmente las organizaciones de trabajadores/as formales. Desde un abordaje cualitativo, contemplando las particularidades de la referencia religiosa, buscaremos comprender la significación de esta marcha para la CTEP y su lucha sectorial, en un contexto de reorganización del mapa político argentino por la llegada de la alianza Cambiemos al gobierno.

Palabras clave: Economía Popular, Acción Colectiva, San Cayetano, Cambiemos, Movimientos Sociales.

Abstract: In this article, we propose to see how, since the march of San Cayetano for Peace, Bread, Land, Roof and Work (2016), a new social and political scenario was opened for the Central of Workers of the Popular Economy (CTEP). Here we highlight three aspects. First, the visibility that the organization gained, as well as the social sector it represents, and its demands, through the march. Secondly, the role of this mobilization in strengthening the links between the different organizations of the Popular Economy. And thirdly, the approach to other social sectors, mainly the organizations of formal workers and ecclesiastical sectors. From a qualitative approach and assuming the particularities of a religious reference, we will seek to understand the significance of this event for the CTEP and its sectoral struggle, in a context of reorganization of the Argentine political map due to the arrival of the Cambiemos alliance to the government.
\end{abstract}

Keywords: Popular Economy, Collective Action, San Cayetano, Cambiemos, Social Movements. 


\section{INTRODUCCIÓN}

\subsection{De qué se trata y qué nos preguntamos}

La festividad de San Cayetano, Santo de la Providencia, Patrono del Pan y el Trabajo, es considerada una de las celebraciones más importantes de la cultura religiosa de la Argentina. Cada 7 de agosto, miles de devotos/as se dirigen a su santuario en Liniers, y tras varias horas de espera, llegan a los pies del santo para pedir trabajo o agradecer haberlo conseguido y/o conservado. Como sucede con otras figuras, San Cayetano pasa a ser el receptor de pedidos que, con frecuencia, surgen de demandas no resueltas ni atendidas por el Estado; se pide su intermediación divina asumiendo que la solución no vendrá del plano de "lo terrenal", de lo político-institucional. Sin embargo, en el hecho que decidimos abordar ocurrió algo singular; a través del santo se canalizaron demandas de un sector social determinado, se dirigieron al poder político y se reclamó la intervención del Estado. Se le pedía al santo, pero también se buscaba como interlocutor a la principal institución en el plano terrenal. El 7 de agosto de 2016 diversas organizaciones sociales, entre ellas la Confederación de los/as Trabajadores/as de la Economía Popular (CTEP), convocaron a participar de dicha festividad bajo el lema "de San Cayetano a Plaza de Mayo por Paz, Pan, Tierra, Techo y Trabajo". Su objetivo principal era impulsar la Ley de Emergencia Social, que contemplaba políticas paliativas destinadas a los/as trabajadores/as de la Economía Popular.

La CTEP es una organización político-sindical que agrupa a los/as trabajadores/as excluidos/as del mercado de trabajo formal en Argentina. Esta Confederación, nacida en 2011, logró mayor visibilidad en estos últimos años debido a los conflictos generados por las políticas regresivas del gobierno electo en 2015, encabezado por Mauricio Macri. En los primeros meses del 2016 ya se vislumbraba una caída del poder adquisitivo de los/as trabajadores/as vinculada a la devaluación y la quita de subsidios estatales a las tarifas (Varesi, 2016), que ponía en alerta a la sociedad argentina. A pesar de esto, según el Observatorio de la Deuda Social de la Universidad Católica Argentina (UCA) este primer año de gobierno de Cambiemos se caracterizó no tanto por afectar al trabajo formal sino por el aumento de la subocupación, la inestabilidad laboral, la precarización del trabajo informal y la caída del ingreso de los sectores populares de la Argentina; así, en el informe de esta institución, se destacaba el aumento significativo de la indigencia y la pobreza (Salvia, Coord., 2017). Esta situación, sumada al carácter beligerante del discurso del nuevo gobierno hacia las organizaciones sociales y sindicales, potenció el carácter defensivo de las organizaciones de los sectores más perjudicados, las de la economía popular e informal.

En este trabajo analizaremos la participación de la CTEP en la festividad religiosa de San Cayetano de 2016, atendiendo a lo que significó para esta organización popular en ese escenario político y social de la Argentina.

Entendemos que, si bien la festividad de San Cayetano cuenta con años de tradición en la cultura argentina, este hecho cobra una significación particular por la inédita convocatoria de las organizaciones de la Economía Popular al Santuario. Dentro del variado repertorio de protestas durante el gobierno de Cambiemos, destacamos ésta como distintiva por dos razones. Por un lado, porque además de visibilizar las demandas de un sector social en particular, fue una de las primeras movilizaciones masivas en contra de las políticas del gobierno que reunió a una diversidad significativa de actores políticos y sociales (Abal Medina, 2017; Giménez Beliveau y Carbonelli, 2017). Por otro lado, por su referencia a elementos religiosos, recurso que seguirá vigente en diferentes actos durante los años siguientes. Así, la movilización de 2016 involucró diversos aspectos de la realidad argentina: la religiosidad popular, la lucha gremial, la situación socioeconómica, la cultura popular y la visibilidad de la economía popular en la escena política del país.

Tomando esta festividad en su complejidad y en las diferentes significaciones que tuvo para la organización abordada, haremos especial hincapié en tres aspectos. Por un lado, las repercusiones que tuvo para la CTEP en el marco de sus luchas reivindicativas y sectoriales, y su posicionamiento en el escenario nacional como 
nuevo interlocutor hacia los poderes políticos: el Ejecutivo y el Legislativo. Por otra parte, cómo la marcha de San Cayetano visibilizó y consolidó la unidad entre las organizaciones de la Economía Popular. Por último, cómo esta movilización permitió afianzar sus vínculos con organizaciones de trabajadores/as formales. Este desarrollo estará atravesado por interrogantes en torno a cómo una convocatoria referenciada en una creencia religiosa pudo visibilizar a las organizaciones de la Economía Popular y profundizar los vínculos entre diversos sectores sociales. ¿Qué es lo que los hizo confluir allí? ¿Fue un punto de partida o la síntesis de un proceso que ya venía gestándose? ¿Tuvo un rol significativo la referencia a San Cayetano? Y por otro lado, interrogantes sobre cómo lo religioso y lo político se vinculan en este hecho social en particular, en el que confluyen diferentes actores e instituciones, en un contexto signado por un cambio de gobierno.

\subsection{Precisiones metodológicas y conceptuales ${ }^{1}$}

Para responder a nuestras preguntas de investigación realizamos un abordaje cualitativo, recurriendo a documentos de la CTEP y a entrevistas de nuestra autoría y de medios de comunicación a algunos de sus referentes. Sumamos la lectura de diversos trabajos académicos que permiten no sólo complejizar el análisis en torno a la acción colectiva sino también reconstruir la situación socio-económica que fue escenario de la Marcha de San Cayetano de 2016.

A la hora de querer comprender en su profundidad este fenómeno, es necesario recurrir a los estudios sobre acción colectiva, desde autores como Charles Tilly (1978), Alberto Melucci (1999) y Gerardo Munck (1995) hasta trabajos más contemporáneas centrados en la identidad colectiva (Retamozo, 2011; Natalucci, 2012; Schuttenberg, 2012). En este marco, es de gran ayuda analítica retomar el concepto de "función profética" (Melucci, 1999), que hace referencia a la capacidad de ciertos hechos de anunciar a la sociedad y al sistema político la existencia de una realidad problemática no visible, en la que no sólo se lucha por necesidades materiales sino también se expresan proyectos simbólicos y culturales. Este recurso nos permitirá comprender el impacto que tuvo la marcha de San Cayetano por Paz, Pan, Tierra, Techo y Trabajo en la realidad argentina y para la CTEP en particular, excediendo la mera demanda material del sector. También será oportuno traer el concepto de "repertorios de acción colectiva" (Tilly, 1978) para entender por qué se eligió esta festividad y no otra, y su rol en el acercamiento entre distintos actores sociales. Y en relación con esto último, comprender qué involucra el lema de la marcha, cómo podemos interpretarla en términos de "demanda articulante" (Retamozo, 2011) y a qué o a quiénes articula. Sumado a esto, partimos de análisis que estudiaron la desinstitucionalización de las relaciones salariales, producto de las transformaciones en el mundo del trabajo, y su consecuencia en los espacios de socialización. Este proceso significó el pasaje de "la fábrica al barrio" e impactó en los repertorios de acción colectiva de los sectores populares (Merklen, 2005; Svampa, 2005). Autores como Merklen reflexionaron en torno a cómo reconstruir esos lazos que antes se anclaban en la filiación salarial y sindical, y allí encontraron el rol del territorio, de la cultura popular, los nuevos métodos de protesta, etc. Un elemento central de la cultura popular es la religiosidad y al encontrarla presente en el fenómeno que abordamos en este trabajo decidimos indagar en el rol de esta referencia en la acción colectiva de una organización popular.

En paralelo, y atendiendo a la centralidad que aquí tiene la religiosidad popular, nos posicionamos en sintonía con perspectivas que buscan comprenderla en el marco de la construcción del lazo social y en relación con el ámbito de lo político. Respecto de esto último, se entienden la esfera religiosa y la política en una relación de permanente diálogo y constitución mutua (Donatello, 2006; Mallimaci, Esquivel y Giménez Beliveau, 2009; Giménez Beliveau y Carbonelli, 2017). Estas posturas evitan caer en reduccionismos, esencialismos y determinismos, rechazan enunciados apriorísticos en torno al carácter alienante o emancipador de las religiosidades (Donatello, 2005; Mallimaci, 2013) pero encuentran en ciertos ejemplos la posibilidad de pensar el rol de la fe en el salto a la acción política (Dri, 2003; Wainstock y Derqui, 2003; Giménez Beliveau y Carbonelli, 2017) o la potencialidad política de la festividad religiosa (Moore, 
2014). En ese sentido, autores como Giménez Beliveau y Carbonelli (2017) interpretaron la movilización de San Cayetano como un termómetro informal de la situación social del país en la que, por las características particulares de este santo y la trayectoria histórica de la festividad, se consolida como un nodo de convergencia entre actores sociales diversos, potenciando "las capacidades de proyección de los reclamos hacia espacios sociales y políticos" (2017, p. 61). Sumado a esto, para comprender en su complejidad los fenómenos socio-religiosos se vuelve necesario recurrir a trabajos que estudiaron la relación entre los contextos sociales y económicos, las instituciones eclesiales y los gobiernos de turno (Mallimaci, 2000; Carbonelli, Follari, Esquivel, Isuani, Margari, Ortiz, Salinas, Vezzosi; 2013).

Por otro lado, es importante para nuestro análisis contemplar el contexto económico, político y social en la Argentina de 2016, cuando el gobierno impulsó políticas pro-empresariales y de ajuste económico, que significaron una amenaza de desempleo y un ataque al poder adquisitivo de los/as trabajadores/as (Varesi, 2016; Zicari, 2016; Pérez y López, 2018). A pesar de esto, y de que el gobierno no contaba con las mayorías en las calles y en el ámbito legislativo (Vommaro y Gené, 2017), el 2016 no fue un año de conflicto social alto (Varela, 2017) y las movilizaciones realizadas no fueron impulsadas por la Confederación General del Trabajo (CGT). En este marco, las organizaciones de la Economía Popular tomaron un rol fundamental al aprovechar la oportunidad para visibilizar su realidad en las calles y llegar al Congreso.

Estas organizaciones vienen siendo objeto de estudio desde hace varios años. Entre finales de siglo XX y principios del siglo XXI, fueron estudiados sus procesos de organización como desocupados/as o piqueteros/ as, atendiendo a sus vínculos con las organizaciones sindicales (Palomino, 2005) e indagando en los elementos identitarios en el marco de la acción colectiva piquetera (Merklen, 2005; Retamozo, 2006) o en los procesos de reordenamiento con la llegada del gobierno kirchnerista (Moreno, 2011; Schuttenberg 2012; Natalucci, 2012). Más adelante, algunos trabajos profundizaron en la incipiente organización de la Economía Popular en Argentina y principalmente en la CTEP. Entre estos trabajos, algunos analizaron este fenómeno desde una perspectiva más económica y social, como Grabois (2013) o Maldovan Bonelli, Ynoub, Fernández Mouján y Moler (2017), que se enfocaron en las políticas públicas destinadas a este sector social; mientras que Fernández Álvarez (2016) y Toffoli (2017) se centraron en los procesos de consolidación y desarrollo organizacional y político. Otras autoras abordaron su irrupción en el escenario social en la Argentina y los vínculos con el sindicalismo tradicional (Abal Medina, 2017; Natalucci y Morris, 2019). En esas lecturas se evidenciaban los debates en torno al trabajo vinculados a las posibilidades de articulación organizativa entre los trabajadores/as asalariados/as y los/as de la Economía Popular. Por su parte, Muñoz (2018) indagó en el vínculo de la CTEP con los gobiernos de turno, y Muñoz y Villar (2017) analizaron sus repertorios de acción y conflicto. Por otro lado, trabajos como el de Bruno (2016) o Carbonelli y Giménez Beliveau (2016) indagaron en los vínculos entre religión y política en esta Confederación.

En función de este recorrido, buscamos comprender la Marcha de San Cayetano por Paz, Pan, Tierra, Techo y Trabajo, convocada por la CTEP y otras organizaciones populares, en función de lo que significó este hecho político para esta organización en particular y en la realidad argentina de 2016. Y en términos más generales, hacer un aporte a los estudios sobre acción colectiva, atendiendo a elementos como la religiosidad, y haciendo eje en las particularidades de esta Confederación en los repertorios de movilización y acción política en la Argentina contemporánea.

\section{2. ¿QUIÉNES Y POR QUÉ MARCHAN EN NOMBRE DE UN SANTO?}

\subsection{Cómo llegamos: Los orígenes de la CTEP y el contexto 2016}

Durante los años 90, en la Argentina se consolidó un proceso de "modernización excluyente" (Svampa, 2005) que confirmó el rumbo iniciado con la dictadura cívico-militar en 1976: una sociedad profundamente 
empobrecida, desigual y fragmentada, signada por la desestructuración del mercado de trabajo y en la cual el trabajo asalariado, registrado y estable ya no era la relación laboral predominante (Grabois, 2013). Frente a contextos de fragmentación dentro del mundo laboral y de debilitamiento del Estado argentino como integrador social -con su consecuente impacto en sus tareas redistributivas-, se fueron gestando nuevos procesos de resistencia y organización que han marcado a fuego el escenario político y social de nuestro país (Palomino, 2005).

El gobierno que llegó luego de la crisis del 2001 y del interinato de diversos presidentes, encabezado por Néstor Kirchner, tuvo sustantivos logros en la reversión de la situación social pero a su vez tropezó con límites marcados por la estructura económica, social y política del período precedente. Las políticas redistributivas favorables a los/as trabajadores/as, la creación de nuevos puestos de trabajo y los incrementos salariales encontraron obstáculos cuando disminuyó la capacidad ociosa: el crecimiento se estancó y lo mismo ocurrió con la creación de empleo registrado (Abal Medina, 2017). En este marco los sectores informales, antes piqueteros, ahora excluidos del sistema laboral formal, se consolidaron como beneficiarios de políticas sociales no salariales que mejoraron su calidad de vida, pero no modificaron su lugar en la estructura económica y social (Piva, 2018). Como también señalan Natalucci y Morris (2019), las diversas políticas implementadas por el gobierno permitieron mejorar las condiciones de vida de grandes segmentos de la sociedad argentina pero profundizaron la brecha al interior de los sectores populares entre trabajadores/as formales con derechos y los/as receptores/as de políticas sociales. Estos/as últimos/as buscaron formas alternativas de garantizar su subsistencia por medio de otras actividades económicas y sus formas de organización respectivas. Con el propósito de representar a estos/as trabajadores/as, surgió en 2011 la Confederación de los/as Trabajadores/as de la Economía Popular. Tal como reconstruye Toffoli (2017), con la intención de nuclear, dar impulso y fortalecer las demandas del sector y hacerlas llegar al gobierno nacional, comienza a gestarse este nuevo proceso organizativo, encarnando experiencias previas, que Paula Abal Medina (2017) sintetizó en tres figuras: "la soledad del desocupado, la acción directa y disruptiva de puebladas y del piquetero, y la institucionalización débil e incipiente del trabajador de la Economía Popular” (2017, p. 22). La diferencia de esta última figura radica en la auto-percepción y necesidad de reconocimiento en tanto trabajadores/ as fuera de la economía de mercado (Muñoz, 2018). En relación con ello, en un primer momento los/as promotores/as de esta herramienta político-gremial tuvieron la intención de sumarse la CGT, algo que se vio imposibilitado por la falta de consenso al interior de esta última en torno al debate sobre la representación de los/as trabajadores/as informales.

En relación con la composición interna de la CTEP podemos encontrar una matriz político-ideológica en la que confluyen tres corrientes: la nacional popular, la izquierda y el cristianismo (Toffoli, 2017). Esos tres elementos le dan una forma particular a la identidad de la organización pero no anulan la heterogeneidad ideológico-política en su interior ni sus respectivas discusiones en la práctica política. Entre las organizaciones que constituyen la Confederación podemos destacar el Movimiento de Trabajadores/as Excluidos/as (MTE), el Movimiento Evita, el Movimiento Nacional de Empresas Recuperadas, Movimiento Popular La Dignidad, el Frente Popular Darío Santillán, Patria Grande, el Movimiento Nacional Campesino Indígena, Misioneros de Francisco, etc. Entre otras razones, la convivencia fue posible por la libertad de acción para posicionarse políticamente ante el gobierno de Cristina Fernández (lo cual no estuvo exento de tensiones) y por la unificación bajo la demanda de reconocimiento como trabajadores/as con plenos derechos, definición que se irá afianzando con el tiempo (Muñoz, 2018).

En el año 2015 asumió la alianza Cambiemos encabezada por Mauricio Macri. El cambio de rumbo económico y político se hizo sentir a los pocos meses de su asunción con el fin del llamado "cepo cambiario" que significó una gran devaluación, la quita de retenciones a las exportaciones, la quita de subsidios a las tarifas de servicios públicos, la energía y el transporte, los despidos en diversas áreas ministeriales y la persecución a ciertos dirigentes vinculados al proceso político anterior (Varesi, 2016). El escenario se recrudeció para los/as trabajadores/as en general pero el impacto fue mucho mayor para los sectores más precarizados, cuyas 
condiciones de vida se pauperizaron significativamente. Muestra de ello fue el aumento de los índices de pobreza e indigencia en cuestión de meses; algo que profundizaría la necesidad de recurrir a políticas de asistencia estatal para garantizar su subsistencia económica (Salvia, coord., 2017). En este sentido, Emilio Pérsico, dirigente del Movimiento Evita y referente de la CTEP, manifestaba: "Primero se perdió la changa, por expectativa del ajuste; después vino el ajuste, después vino la inflación, ahora la inflación y la recesión, después el tarifazo, y todo expresa un deterioro social" (Diario La Capital, 21/8/2016). Así, este sector, que era el eslabón final de una cadena de dependencias con respecto a los mermados ingresos y niveles de consumo de los/as trabajadores/as formales, fue uno de los más perjudicados por las políticas del nuevo gobierno.

Frente a este contexto, durante el primer año de gestión de Cambiemos diversos sectores sociales comenzaron a cuestionar las políticas implementadas pero no hubo cambios significativos en relación con los conflictos laborales (Varela, 2017). En ese escenario, se realiza el 7 de agosto de 2016 la marcha de San Cayetano, una de las primeras movilizaciones masivas que, a través de una festividad religiosa, reunió a distintos actores sociales, críticas a las políticas del gobierno de turno y demandas concretas de un sector que veía profundizar la pauperización de sus condiciones de vida.

\section{2 ¿Por qué San Cayetano? CTEP, Francisco y religiosidad}

Antes de dar paso al análisis de lo que significó la marcha de San Cayetano para la CTEP, su lucha reivindicativa y la articulación con otras organizaciones del mundo del trabajo, destacaremos algunos aspectos para complejizar el vínculo entre lo religioso y lo político en esta organización, pues la referencia religiosa es un elemento significativo en el hecho social que abordamos.

Por un lado, un elemento ineludible para el análisis es el rol relevante que ha tenido el papa Francisco para los movimientos populares de América Latina y su impacto en la realidad política y social argentina. Su figura ha dado gran respaldo a estos movimientos sociales, principalmente mediante la apropiación del lema "Tierra, Techo y Trabajo" -demandas históricas y elementales de las organizaciones populares-, el reconocimiento de la figura del/la trabajador/a de la economía popular como víctima de la "cultura del descarte" y la organización de los Encuentros Mundiales de Movimientos Populares (EMMP) (Muñoz y Villar, 2017). Pero previamente a su papado, él ya se encontraba vinculado a algunas de las organizaciones que integraban la CTEP. Éstas y grupos de la Iglesia Católica ya compartían trabajo territorial en las villas y asentamientos, y ahora los encontraba la línea política, ideológica y teologal del papa argentino. En este sentido, la aparición de Francisco significó una oportunidad identitaria concepto que retoman Carbonelli y Giménez Beliveau (2015) de Natalucci (2012), para explicar el rol de esta figura en la recuperación y resignificación de tradiciones y filiaciones identitarias. En relación con esto, podemos evocar las palabras de un entrevistado:

"La articulación con la Iglesia, que en la prédica de la palabra de Francisco, en la celebración de la palabra de Francisco, en la reivindicación de los compañeros que están sufriendo y también el reconocimiento de que muchos de ellos están organizados, se nos abrió un canal donde la agenda social es la misma." (G. Onorato, en entrevista realizada por el autor, 2/3/2019)

El discurso de Francisco fue, entonces, otro punto de encuentro entre estas organizaciones y algunos sectores de la Iglesia Católica Argentina que comenzaban a exponer su valoración crítica de las políticas implementadas por el gobierno de Cambiemos. Esta actitud crítica hacia políticas de corte neoliberal no era nueva en la Iglesia (Mallimaci, 2000), lo cual daba cierta legitimidad a la voz eclesial como actor denunciante en contextos de crisis (Carbonelli et al, 2013).

Por otro lado, es importante retomar el componente cristiano, presente en la matriz político-ideológica de la CTEP (Tóffoli, 2017) ya que nos permite complejizar la presencia de lo religioso en la constitución identitaria de la organización. Este componente podemos encontrarlo en publicaciones de su web oficial, en sus cuadernillos de formación, en imágenes y símbolos que son llevados a las movilizaciones, y en los discursos de algunos/as dirigentes (Bruno, 2016). A su vez, en el marco de la heterogeneidad que compone 
la CTEP, existen organizaciones como Misioneros de Francisco, en las que se articula la práctica religiosa con la militancia socio-territorial (Carbonelli y Giménez Beliveau, 2016), o dirigentes como Emilio Pérsico, dirigente del Movimiento Evita y fundador de Misioneros de Francisco, y Juan Grabois, referente del MTE; ambos con fuertes vínculos con el papa. Pero, aunque el componente cristiano se encuentre presente en la organización, compartirlo no es condición sine qua non para participar de ella ya que el nodo de convergencia es el sujeto social que buscan representar: los/as trabajadores/as de la Economía Popular.

En relación con las diferencias que existen al interior de la Confederación sobre este tema, cabe destacar que los entrevistados aludieron a la reticencia de algunos sectores a realizar una marcha en nombre de un santo, haciendo referencia al carácter alienante y/o negativo de lo religioso en el marco de la práctica política; pero que dicha discusión había sido saldada por la necesidad de construir espacios amplios de articulación y visibilización para la Economía Popular. En una reciente entrevista, Esteban "Gringo" Castro, Secretario General de la CTEP, frente a la pregunta acerca del diálogo entre las organizaciones sobre el tema religiosidad declaraba: "Por suerte hay mucho respeto. Primero porque peleamos juntos, nos reprimen juntos, y vamos en cana juntos. Tenemos una hermandad en la lucha" (FactorFrancisco.org, 02/05/2020).

Por otro lado, cuando nos preguntamos el porqué de la referencia a este santo en la movilización, encontramos algunos aspectos que podemos señalar sucintamente. En primer lugar, el día de la marcha de San Cayetano, en el Santuario se realizó una misa en la cual representantes de cada una de las organizaciones convocantes fueron bendecidos por el cura de la Parroquia, lo que explicitaba el apoyo a la iniciativa. Este santuario lleva consigo una historia de larga data que da muestra de su rol social y político en el territorio. Ejemplo de ello son los vínculos con la Juventud Obrera Católica (JOC) o los encuentros con representantes sindicales como Saúl Ubaldini, algo que se vio materializado en el acto convocado en 1981. En este sentido, el espacio elegido para iniciar la movilización ya tenía antecedentes que permitían vincularla a las demandas de los/as trabajadores/as y sus organizaciones. En segundo lugar, según los testimonios de los entrevistados, la elección del santo estaría vinculada a su masivo conocimiento, a su presencia relevante en los sectores populares y su vínculo con la tradición política argentina. En relación con esto, pero haciendo énfasis en el peso simbólico de las referencias religiosas para neutralizar discursos estigmatizantes e interpelar a sectores sociales ajenos a la organización política, el mismo entrevistado expresaba:

“(...) tiene una recepción distinta, porque no es lo mismo cuando vos marchás por la calle con la Virgen, con San Cayetano, con el Gauchito Gil... hasta cuando te enfrentás con la policía. La Policía Federal tiene en su escudo la Virgen de Luján, entonces vos te parás enfrente de la Policía Federal con la Virgen y eso te presenta de otra forma." (G. Onorato, 2/3/2019)

En la misma línea, el "Gringo" Castro hacía la misma referencia: "En otra manifestación, se generó un encontronazo con la policía que los dirigentes mismos tratamos de disipar, y ahí, en plena negociación, Vilma Ripoll del MST me dijo: '¡Che, Gringo, no trajiste la Virgen esta vez!'” (FactorFrancisco.org, 02/05/2020).

De estos dichos podría entenderse un uso meramente instrumental de la religiosidad para hacer política. Aunque esta afirmación bien podría matizarse con la postura que dejan ver los entrevistados al sostener que, en el marco de la organización de los sectores populares, la intención es ir a la par de sus grados de conciencia y politización: "Uno no puede atacar la religiosidad popular en pos de un proyecto político emancipador. (...) para nosotros es importante que los compañeros crean en ciertas figuras. Es importante porque ellos conviven con una religiosidad que los hace seguir para adelante" (G. Onorato, 2/3/2019).

Ahora bien, entendiendo que la CTEP no es una comunidad religiosa sino que su práctica concreta se vincula a las demandas de los/as trabajadores/as de la Economía Popular y a la consolidación política y organizacional del sector, nos preguntamos: ¿cómo se traduce la referencia religiosa a la acción política? Al respecto, decía un entrevistado:

"Así como hay que ir a Sanca, también hay que ir a Desarrollo Social y decirle 'Señora Stanley ${ }^{2}$ necesitamos trabajo para toda esta cantidad de gente que no va a conseguir trabajo nunca'. Entonces ¿va a solucionar el problema del trabajo ir a San 
Cayetano? No, va a cohesionar a distintas organizaciones, distintas fuerzas para ir a pedirle trabajo a quien hay que ir a pedirle trabajo, en este caso es el Estado." (R. Bernales, en entrevista realizada por el autor, 31/1/2019).

Lo que aporta el testimonio es que la religiosidad en sí misma no consolida la acción colectiva de los/as trabajadores/as de la Economía Popular. El hecho de que la voluntad de quienes organizaron la marcha no haya sido la de quedarse en el acto de devoción religioso nos permite comprender la religiosidad en la esfera política fuera de análisis fetichistas que le atribuyen un carácter alienante. La participación de la CTEP en la festividad de San Cayetano permitiría un reconocimiento entre pares a través de elementos identitarios comunes, en este caso la religiosidad popular, que da más sustento a la acción colectiva. La construcción de una identidad colectiva mediante la movilización de sentidos y resignificaciones sobre la realidad que viven los sectores populares (sus necesidades, problemáticas, sus demandas, etc.) impulsaría a estos sectores a dar un salto al campo de la acción y consolidarse como sujetos de acción (Dri, 2003; Retamozo, 2006); todo esto, mediado por la organización.

En síntesis, la marcha de San Cayetano exponía el acercamiento entre la CTEP y sectores de la Iglesia Católica, la referencia con el papa Francisco y una postura en torno a los vínculos entre religión y política, que aunque no era compartida de manera unánime, tenía más fuerza a la hora de la toma de decisiones y por tanto para expresarse en la esfera pública.

A su vez, la realización de esta marcha tendría un impacto tanto hacia el interior de la CTEP, haciendo hincapié en creencias colectivas que permitirían fortalecer la acción organizativa, como hacia afuera, pues la referencia a una creencia religiosa permitiría no sólo legitimar su lucha sino también proyectar sus reclamos hacia ámbitos sociales y políticos (Giménez Beliveau y Carbonelli, 2017), algo que veremos más explícitamente en el siguiente apartado.

\section{La marcha de San Cayetano: la CTEP y la lucha por la emergencia social}

De acuerdo a lo reportado por los medios de comunicación que lo cubrieron y la fuente oficial de la CTEP, el 7 de agosto de 2016, cien mil personas participaron de la movilización de 13 kilómetros, desde el santuario de San Cayetano hacia Plaza de Mayo, bajo la consigna "Paz, Pan, Tierra, Techo y Trabajo".

El reclamo central de la marcha era la sanción de la Ley de Emergencia Social, que contemplaba la creación del Salario Social Complementario, el aumento de las asignaciones, la creación de un millón de puestos de trabajo, del "Consejo de la Economía Popular y el Salario Social", y del "Registro Nacional de la Economía Popular (RENATREP)", con el correspondiente financiamiento de esas instituciones. Las organizaciones convocantes demandaban al poder político y legislativo la implementación de políticas específicas para el sector, en un contexto económico complicado para los/as trabajadores/as en general, y para los sectores informales y de la Economía Popular, en particular. Siguiendo a Melucci (1999), podríamos pensar que esta movilización adquirió una función profética al anunciar frente a la sociedad una realidad desatendida por el sistema político, visibilizando a estos/as trabajadores/as no reconocidos/as por el Estado y sus demandas. La Ley de Emergencia Social comenzaba a discutirse y la marcha buscaba ser un método de presión mediante la visibilización en las calles de un sector que exigía con urgencia el tratamiento de dicho proyecto.

La alianza gobernante comenzó su gestión sin mayoría parlamentaria ni consenso social necesario para realizar grandes medidas económicas de ajuste o de shock. Por esta razón, en los primeros años -a pesar de haber recurrido al Decreto de Necesidad y Urgencia para implementar políticas, salteándose al Poder Legislativo- el gobierno tuvo que construir consensos con distintos sectores de la oposición (Zicari, 2016; Vommaro y Gené, 2017). Frente a ello existieron distintas posturas acerca de cómo vincularse con el gobierno; algunos espacios del peronismo o de los gobiernos provinciales optaron por acordar ciertas leyes y otros sectores optaron por una oposición más antagónica a las propuestas oficialistas. En paralelo, se gestaron ciertas instancias de unidad opositora para la aprobación de algunas medidas defensivas, como la Ley Antidespidos, vetadas por el presidente días después de su aprobación (Zicari, 2016). 
En este escenario, luego de las idas y vueltas del proyecto en las comisiones de labor parlamentaria, en diciembre de 2016 se aprobó la Ley de Emergencia Social con 227 votos a favor, 1 rechazo y 4 abstenciones en Diputados (La Nación, 7/12/2016), y por unanimidad en Senadores con 49 votos a favor (La Nación, 14/12/2016). En este sentido, es destacable la construcción de consensos que esta ley supuso por parte de sus promotores/as, que contaban con algunos/as representantes en ambas cámaras, lo que facilitó el ingreso del proyecto y su posterior debate.

En el marco de las discusiones en torno a cómo hacer política en este contexto abierto después del 2015, la Ley de Emergencia Social recibió cuestionamientos en torno a su carácter paliativo y la utilización política que el gobierno hacía de ella. A pesar de esto, para sus promotores/as ésta era una victoria material pero fundamentalmente simbólica en la lucha por el reconocimiento de la Economía Popular y la transformación de los sentidos existentes sobre este tipo de trabajo. Este proceso al interior de la CTEP es denominado por Fernández Álvarez (2016) como noción de bienestar(es), allí los logros vinculados a las condiciones de trabajo y de vida fomentan horizontes de expectativas que, al ser compartidos, impulsan la construcción de sentidos en torno a la necesidad de fortalecer sus procesos organizacionales. En este sentido, la consolidación de organización es considerada como un logro en sí mismo por los dirigentes de la CTEP, pues da pie a la construcción de una identidad como trabajadores/as y por tanto como impulso a la lucha por derechos como tales. Así, podemos entender la Ley de Emergencia Social en el marco de lo que Maldovan Bonelli et al (2017) denominaron "los dos hitos del desarrollo organizativo de la CTEP". El primero fue la adjudicación de la Personería Social en 2015, el reconocimiento legal en tanto organización de trabajadores/as; el segundo, la sanción de dicha Ley, gracias a la visibilización lograda en la Marcha de San Cayetano y la apertura del diálogo con el gobierno. En medio de las tensiones entre la dura crítica al proyecto político-económico macrista y la necesidad de recursos para que la propia organización subsistiera (Muñoz y Villar, 2017), entre la estrategia y la identidad (Munck; 1995), este diálogo le significó duras críticas a la CTEP. Lo cierto es que, en parte, este medio posibilitó evitar el veto de la Ley, como también entre 2016 y 2017 garantizó el presupuesto para diversas políticas sociales, aunque no bastó para contener el impacto de las políticas macroeconómicas del gobierno en las condiciones de vida de los sectores populares (Vommaro y Gené, 2017; Muñoz, 2018). Esta apertura del diálogo por parte del gobierno fue interpretada por Vommaro y Gené (2017) como un gesto necesario frente a la amenaza de conflictividad social que auspiciaban las movilizaciones y piquetes de estas organizaciones.

En este marco, la marcha vino a visibilizar los niveles de organización de este sector social e instalar en agenda sus demandas, durante el inicio de un gobierno que no generaba apoyos en la dirigencia de la CTEP. Esto le permitió a la Confederación consolidarse en el escenario nacional pero también hacia su interior; es decir, a pesar de que ciertas discusiones siguieron vigentes, las políticas del gobierno de Mauricio Macri reafirmaron cierta unidad en el discurso de la organización, lo que Tofffoli (2017) definió como "el acuerdo sobre el enemigo" (2017, p. 78), que entre fines de 2016 y principios de 2017 comenzó a unificarse, luego de un período de dispersión (Muñoz y Villar, 2017). Esta lógica de unificación de criterios en torno al enemigo común también se reprodujo en el vínculo con otras organizaciones sociales y sindicales.

\section{El Triunvirato Cayetano}

La marcha de San Cayetano 2016 fue convocada por lo que luego se denominó el "Triunvirato Cayetano" o "Los Cayetanos", compuesto por la CTEP, la Corriente Clasista y Combativa (CCC) y Barrios de Pie (BP), organizaciones cuyos recorridos políticos difieren sustancialmente.

La CCC, fundada en 1994, es una rama territorial del Partido Comunista Revolucionario. Junto con la Federación de Tierra y Vivienda eran consideradas las organizaciones territoriales más grandes de la provincia de Buenos Aires a principios de siglo (Merklen, 2005). Buscaba representar, desde una perspectiva clasista, a todos/as los/as trabajadores/as, fundamentalmente a los/as que se encontraban desocupados/ 
as. Desde sus orígenes, ya mostraba predisposición a alianzas tácticas con otras organizaciones y a la vinculación instrumental con los gobiernos de turno en pos de la obtención de políticas asistenciales y recursos organizativos, sin perder la centralidad identitaria del comunismo maoísta (Moreno, 2011). En lo que se refiere a sus posicionamientos políticos, este espacio se mostró más distante que otras organizaciones al gobierno de Néstor Kirchner y se opuso al de Cristina Fernández, principalmente a partir del conflicto iniciado por la Resolución 125/08, de retenciones móviles al sector del agro. Por su parte, Barrios de Pie fue creada en 2001 como un desprendimiento territorial de la organización política Libres del Sur. Inicialmente, fue aliada del gobierno de Néstor Kirchner junto a otras organizaciones, pero siempre preservó una autonomía considerable con respecto al espacio político del ex-presidente. En 2007, a través de un proceso de construcción y reconfiguración de su identidad política (Schuttenberg, 2012), terminó alejándose de dicho espacio político y construyó otro camino en la política nacional. No obstante, apoyó algunas políticas implementadas por el gobierno kirchnerista, como la Resolución 125/08.

Aunque encierran temporalidades, idiosincrasias y trayectorias políticas diferentes, la CTEP, la CCC y BP buscaron representar a un mismo sector social que no era reconocido por el Estado como parte del mundo del trabajo (trabajadores/as de programas sociales, campesinos/as, cooperativistas, etc.). Durante el gobierno kirchnerista, las tres organizaciones realizaron diagnósticos diferentes; no obstante, el cambio de gobierno a fines de 2015 instaló un nuevo escenario: la implementación de un discurso de deslegitimación hacia los/ as trabajadores/as y sus sindicatos, y el despliegue de una serie de políticas gubernamentales en esa misma sintonía, que impactaban directamente en las condiciones de vida de los sectores que representaban. Esto permitió una mayor unidad de concepción política entre las tres organizaciones, que contribuyó a soslayar, al menos provisoriamente, algunas de sus diferencias. Fue algo semejante a lo que ocurrió al interior de la CTEP.

Según los entrevistados, la postura de la CTEP centrada en la necesidad de construir unidad a partir de una resistencia de carácter social, no partidaria, por fuera de la grieta kirchnerismo-no kirchnerismo, compartida por la CCC y Barrios de Pie, fue el punto de partida de una alianza que seguiría fortaleciéndose con el correr del tiempo y que logró un punto alto de visibilidad en la marcha de San Cayetano.

Estas tres organizaciones ya se habían encontrado en ocasiones previas: los EMMP, convocados por el Papa Francisco en 2014 y 2015, bajo las consignas de Tierra, Techo y Trabajo, y su réplica nacional realizada en el Santuario de los Santos Latinoamericanos en Lomas de Zamora (2015), que contó, a su vez, con la participación de algunos sectores del sindicalismo. Ese hecho fue un gesto incipiente de lo que luego irrumpiría en las calles el 7 de agosto de 2016, continuando los repertorios de movilización trazados entre la política y la religiosidad popular. En relación con esto, uno de los entrevistados acotaba:

"Podés pensar 'Qué mal que estamos que nos tiene que unir un santo' o 'Qué bueno que a través de la religiosidad popular podamos canalizar pedidos o programas políticos'. Son organizaciones que tienen experiencia y tradiciones políticas totalmente distintas, y que las una un santo, te deja pensando..." (R. Bernales, 31/1/2019).

A partir de la marcha de San Cayetano, se fue consolidando tanto en la esfera pública (comenzaron a ser llamados "los Cayetanos") como al interior del Triunvirato una unidad en resistencia a las políticas del gobierno mediante movilizaciones, entre ellas la repetición cada 7 de agosto de la Marcha de San Cayetano, y en la difusión de propuestas y proyectos legislativos, como la Emergencia Alimentaria, Ley de Infraestructura Social, Ley de Adicciones, Ley de Integración Urbana y la Ley de Agricultura Familiar. Un dato relevante fue la creación del espacio político "En Marcha” lanzado en 2018 por los partidos políticos de algunas organizaciones de la CTEP (Patria Grande, Movimiento Evita, Seamos Libres, entre otras), la CCC, Barrios de Pie y otros partidos relacionados con espacios sindicales como ATE. Por medio de esta herramienta partidaria, estas organizaciones buscaban formalizar su agenda reivindicativa como ejes de campaña para las elecciones presidenciales de 2019. Esta iniciativa fue obturada por distintas contradicciones, entre ellas las referidas a las candidaturas presidenciales a apoyar, sin que esto significara una ruptura visible del triunvirato en torno a la lucha política reivindicativa. La continuidad de esta articulación se evidenció en diciembre 
de 2019 al conformarse la Unión de Trabajadores y Trabajadoras de la Economía Popular (UTEP), como sindicato único del sector y con la ambición de ingresar a la CGT. ${ }^{3}$ En esta línea, uno de sus dirigentes expresaba en el acto de lanzamiento: "Ya no somos más planeros, subsidiados y piqueteros sino trabajadores con propuestas que completan la pata que le faltaba al movimiento obrero" (Gildo Onorato, Página 12, 22/12/2019).

Después de repasar estas instancias de acercamiento y unificación entre estas tres organizaciones, podemos pensar que la marcha de San Cayetano operó como articuladora de la crítica hacia el gobierno de Macri y, a su vez, como multiplicadora de espacios y ámbitos de acción colectiva. A pesar de sus trayectorias y relevancias previas al hecho, fue esta movilización la que posicionó a estos actores en la esfera pública, la que les dio un nombre y los confirmó como un actor ineludible para el nuevo gobierno.

\section{No tan Distintos: SAN CaYetano y las organizaciones SOCiales}

Entendiendo que la relevancia política de la Marcha de San Cayetano se basó no sólo en lo que significó para las organizaciones convocantes sino también en la confluencia de diferentes actores sociales, consideramos necesario destacar la presencia de sectores del sindicalismo y la potencialidad de este encuentro para el fortalecimiento de los vínculos entre estos y las organizaciones de la Economía Popular.

La movilización contó con el acompañamiento de diversos actores de la sociedad civil: organizaciones políticas y sociales, el Partido Justicialista, sindicatos de la CGT -como Canillitas, Camioneros, Bancarios-, las dos Centrales de Trabajadores Argentinos (CTA Autónoma y CTA de los Trabajadores), la Asociación de Trabajadores del Estado (ATE), federaciones estudiantiles, referentes de Derechos Humanos y sectores de la Iglesia Católica Argentina.

En el caso de las organizaciones sindicales, estas se acercaron con la intención de mostrar su disconformidad con las políticas económicas del gobierno de Cambiemos y sus efectos concretos sobre las clases trabajadoras. Estas organizaciones ya habían mostrado ciertas intenciones de acción conjunta el 30 de abril de 2016, cuando la CGT Azopardo, la CGT Alsina y las dos CTA convergieron en una movilización contra el ataque del nuevo gobierno al salario y al empleo, y de la que algunas organizaciones de la Economía Popular participaron aunque no formaron parte oficialmente del acto (Lenguita, 2017; Natalucci y Morris, 2019). Esto nos permite seguir interpretando al rechazo a las políticas de Cambiemos como facilitador de escenarios de unidad dentro del mundo del trabajo.

Para pensar la participación de las CTA en la Marcha de San Cayetano destacamos dos cuestiones. En primer lugar, puede decirse que desde el inicio del gobierno de Cambiemos estas centrales rápidamente se manifestaron en contra de sus políticas, fundamentalmente a raíz de los despidos en el sector público y la política salarial (Lenguita, 2017). En segundo lugar, acompañaron la movilización haciendo énfasis en la importancia de que las organizaciones de trabajadores/as formales contribuyeran en la visibilización de los sectores de la economía popular e informal. Dicho posicionamiento no fue novedoso, ya que esta central durante los años 90 procuró agrupar y representar a los/as trabajadores/as informales y desocupados/as, para lo cual incorporó en su estructura nuevas actividades y demandas, asumiendo que aquellos difícilmente podrían incorporarse al mercado laboral formal (Morris, 2014). Este principio de afiliación permitió que otros sectores de la economía, además de los/as trabajadores/as en relación formal de dependencia, pudieran afiliarse y organizarse, al tiempo que abría un campo de disputa en torno a la representación monopólica de la CGT. A pesar de esta apertura, desde la CTEP no contemplaron la posibilidad de sumarse a dicha central (Natalucci y Morris, 2019), algo que hemos podido constatar en las entrevistas realizadas, en las que se hacía referencia a esto en términos de romper el movimiento obrero.

Por su parte, la participación de la CGT en la marcha amerita otras consideraciones. En primer lugar es importante retomar el antecedente más cercano en torno a la lucha sindical y a la festividad de San Cayetano: la Marcha por Paz, Pan y Trabajo (1981) convocada por Saúl Ubaldini, dirigente de la CGT. En 
aquella ocasión, la tríada conceptual del lema de la marcha hacía referencia a las condiciones económicas y políticas generadas por el gobierno militar. Estas demandas apuntaban a nuclear a diversos sectores de la sociedad argentina en pos de consolidar un colectivo que enfrentase a la dictadura (Marini, 2017). Es decir, esta referencia religiosa ya existía en el repertorio de acción y de memoria colectiva de la CGT, por lo que podemos pensar la marcha a San Cayetano en el marco de procesos de lucha y tradiciones políticas previas, como parte de un "repertorio de confrontación", de formas familiares de acción transmitida cultural e históricamente (Tilly, 1978). La marcha de 2016 no sólo reeditó la convocatoria al Santuario sino también su lema, maridando la fórmula con los conceptos de un escenario transformado. Podemos interpretar la consigna "Paz, Pan, Tierra, Techo y Trabajo" como una "demanda articulante" (Retamozo, 2011), un eje programático que, al ser compartido por el Papa, el sindicalismo y los movimientos populares, permitió un alto grado de entendimiento y articulación entre estos. Así, también podemos pensar este lema como una referencia a sentidos vinculados a la noción de trabajo, con miras a consolidar una alianza en el marco de la acción colectiva (Retamozo, 2006), en este caso entre los/as trabajadores/as formales y los/as de la Economía Popular. Esta combinación dentro del lema nos permite ver, por un lado, el cruce entre política y la religiosidad popular, y por otro, la presencia de lo religioso en la construcción de sentido y memoria colectiva de las clases trabajadoras, la rememoración de un pasado común, en pos de un proyecto de futuro: en nuestro caso, las organizaciones de la Economía Popular, retomando un antecedente de la lucha sindical argentina, interpelarían a otros/as trabajadores/as para potenciar su lucha reivindicativa del presente, con la posibilidad de consolidar una alianza política y programática a futuro. Esta rememoración de tradiciones de lucha previas tendió puentes con un actor central y fortaleció la acción política de la CTEP.

En segundo lugar, para comprender en profundidad este encuentro entre la CGT y la CTEP es necesario repasar la trayectoria vincular entre ellas. Ni bien se constituyó la CTEP, sus referentes aspiraron a integrarse a la estructura organizativa de la CGT. La central sindical se negó a esta solicitud, argumentando la falta de organización de estos sectores y las dudas sobre si su incorporación representaba "avalar la ilegalidad" (Abal Medina, 2017, p. 44); es decir, si el reconocimiento institucional de estas organizaciones significaba una legitimación de relaciones laborales informales que pudiera afectar los derechos de los/as trabajadores/ as formales y el esquema sindical tradicional que defendían (Natalucci y Morris, 2019). Muchos actores sindicales no concebían/conciben a estos/as trabajadores/as como parte del mismo colectivo. En palabras de Abal Medina (2017), eran para ellos "grupos a los que la CGT debía ayudar pero que no integraban el mismo 'nosotros'” (2017, p. 43). Esto no impidió que, luego del cambio de gobierno, la CTEP y algunos sectores de la CGT compartieran actos de protesta, aunque no fuera de manera oficial. Uno de ellos fue la marcha a San Cayetano. Ese mismo 7 de agosto, día del Patrono del Pan y el Trabajo, la CGT emitió un comunicado sobre la situación del trabajo en la Argentina desde la asunción del nuevo gobierno, en el que no hubo referencia a la movilización convocada por el triunvirato Cayetano. Es decir, a pesar de que varios dirigentes de la CGT se acoplaron a la convocatoria de los Cayetanos -entre ellos Hugo Moyano- no hubo un posicionamiento oficial de acompañamiento por parte de la central sindical. Sin embargo, podemos ver que este acercamiento tuvo repercusiones considerables en las discusiones sobre la articulación entre las diversas organizaciones de trabajadores/as. En este sentido, uno de los entrevistados decía:

“(...) si hay un cambio en la mirada del sindicalismo tradicional es reconocer que el mundo del trabajo ha cambiado, y que hoy precisamente el asalariado ya no es el único trabajador. Entonces ya no es el movimiento obrero organizado sino el movimiento de los/as trabajadores/as organizados/as. Eso nos empoderó." (Gildo Onorato, 2/3/2019)

En los meses posteriores a la marcha, se visibilizó un fuerte acompañamiento mutuo: la CTEP adhirió a los paros y movilizaciones de la CGT, y ésta apoyó más visiblemente las manifestaciones y reclamos de la CTEP. Aquí nos permitimos retomar tres hechos que consideramos relevantes como continuidad de este vínculo.

El 24 de septiembre se realizó otra re-edición nacional del EMMP, en el que la CGT abrió las puertas de su sede a las organizaciones de la Economía Popular y a autoridades de la Iglesia Católica. Allí, Héctor Daer, 
uno de los integrantes del triunvirato de la CGT, expresó: "Hemos dado un paso fundamental en entender que la CGT representa a todos los trabajadores", y aclaró "haber entendido hace poco la realidad [de los/as trabajadores/as de la Economía Popular] (...) Asumimos su representación y tomamos sus reclamos en una agenda común" (Página 12, 25/9/16). El 18 de noviembre de 2016 se realizó una convocatoria desde la CGT y las organizaciones de la Economía Popular, bajo el lema "Unidad por la Justicia Social", que contó con el apoyo de entidades como la Confederación General Empresaria de la República Argentina (CGERA) y la Federación Agraria Argentina. Tenía como principal demanda la sanción de la Ley de Emergencia Social. ${ }^{4}$ En ese mismo escenario pudo observarse otro paso en el acercamiento público entre estas organizaciones. "Estamos forjando esa herramienta común entre el sindicalismo organizado y los movimientos sociales y populares de este país" (Notas, periodismo popular, 19/11/2016), decía el último orador del acto, Juan Carlos Schmid, uno de los tres referentes de la CGT, y el más comprometido con esta intención de articular con las organizaciones de Economía Popular. Por último, podríamos nombrar como hecho significativo la creación de la Secretaría de la Economía Popular en el organigrama de la CGT, que fue ocupada por el Secretario General de la Unión Obrera Ladrillera de la República Argentina (UOLRA), Luís Cáceres, de fuertes vínculos con el Movimiento Evita, una de las organizaciones más fuertes de la CTEP.

En correlación con estos hechos, y aunque existen diferentes perspectivas al interior de la organización con respecto a los vínculos con la CGT (Natalucci y Morris, 2019), en 2019, en el lanzamiento de la UTEP se dejó asentado el objetivo próximo de integrarse a la CGT (ctepargentina.org, 21/12/2019). Pero como declara el Esteban "Gringo" Castro, esta iniciativa depende de un proceso más amplio de discusión en torno a la unidad del movimiento obrero: "Hay una nueva configuración de la clase trabajadora que tiene que estar expresada” (Agencia Télam, 23/12/2019).

En relación con lo abordado en este apartado podemos decir que la festividad de San Cayetano fue un elemento articulador entre diversas organizaciones y dirigentes del mundo laboral en un contexto de precarización de las condiciones de vida de los/as trabajadores/as. La referencia a tradiciones de lucha sindical previas, y a este símbolo religioso, con eje en el trabajo, funcionó como escenario de encuentro. En este sentido, tal como señalan Natalucci y Morris (2019), "el escenario abierto a fines de 2015 abrió una ventana de oportunidades para subsanar la distancia entre CGT y CTEP” (2019, p. 189); o, como declaró uno de los entrevistados para este trabajo: "Lo que hizo Macri fue hacer entender, o por lo menos las orgas entendieron, que al final no somos tan distintos" (R. Bernales, 31/1/2019).

A pesar de estos vaivenes, de las discusiones no saldadas al interior de la CGT, las idas y vueltas entre estas dos organizaciones, afirmamos que la Marcha de San Cayetano, como receptáculo de las críticas al gobierno, permitió una importante instancia de acercamiento entre estas confederaciones en tanto organizaciones de trabajadores/as, algo que se iría consolidando con el correr del tiempo, como también potenció, legitimó y visibilizó la acción política de la CTEP en el escenario argentino de 2016

\section{Consideraciones Finales}

A lo largo de este artículo abordamos la Marcha de San Cayetano por Paz, Pan, Tierra, Techo y Trabajo, convocada por las organizaciones de la Economía Popular, destacando algunos aspectos centrales a la hora de intentar comprender la significación de este hecho para la CTEP y para la realidad argentina. Como dijimos anteriormente, el discurso de la CTEP se encuentra atravesado por una particular referencia a elementos cristianos que, aunque no de manera homogénea, se evidencia en los discursos de algunos referentes y en sus repertorios de movilización. Esto nos habilitó a pensarla como función facilitadora de entendimiento con sectores de la Iglesia y, en particular, con la figura del papa Francisco; como también nos permitió reflexionar sobre el porqué de la referencia religiosa en la movilización política. Este santo, vinculado a la problemática del trabajo, enlazó de manera directa con las demandas concretas de los/as trabajadores/as de la Economía Popular, que exigían reconocimiento y políticas específicas para el sector. La masividad de la movilización y la 
diversidad de apoyos recogidos visibilizaron y legitimaron las demandas de la Economía Popular, inscriptas en la Ley de Emergencia Social, y potenciaron la aparición del triunvirato Cayetano en el escenario social y político. Los/as promotores/as de la ley consiguieron construir los consensos necesarios para su aprobación, instalar el sector en la agenda nacional y consolidarse como un interlocutor necesario para el gobierno.

Por otra parte, la consigna "Paz, Pan, Tierra, Techo y Trabajo" hizo confluir el lema del santo, la lucha sindical argentina y las demandas de los movimientos populares ligados al papa Francisco, lo que dio lugar a un potente escenario de unidad. La figura de San Cayetano y la lucha por el trabajo fueron puntos de encuentro entre actores del mundo laboral, las organizaciones de la Economía Popular y las centrales sindicales argentinas, lo que tuvo cierto carácter de novedad dada la postura renuente de la CGT a la articulación con las organizaciones sociales, algo que fue transformándose con la llegada del gobierno de Cambiemos. A su vez, esta referencia religiosa visibilizó los vínculos existentes con sectores de la Iglesia Católica, a través del trabajo territorial y los discursos críticos de Francisco sobre la desigualdad y la exclusión.

Consideramos que estos acercamientos tuvieron un catalizador decisivo: el desembarco, en 2015, de un gobierno con un discurso anti-sindical, neoliberal y con políticas contra los/as trabajadores/as, el cual impulsó repertorios de movilización que sintetizaron la resistencia a dichas políticas. En este trabajo resaltamos la centralidad de la Marcha de San Cayetano como escenario de articulación y potencialidad reivindicativa. Esta tuvo sus efectos en distintas escalas: la consolidación al interior de la heterogeneidad de la CTEP y entre las organizaciones del triunvirato Cayetano, y los acercamientos con otros actores sociales. Este desarrollo podríamos sintetizarlo en palabras de un dirigente de la organización:

"La unidad en la calle, la articulación con la CGT, la articulación con la Doctrina Social de la Iglesia a partir de la Pastoral, es lo que nos permitió a nosotros transformarnos en un articulador, en un interlocutor inevitable para el Estado. Fue la construcción de una unidad que visibilizó una nueva realidad en el mundo de la clase trabajadora, que llegó para quedarse" (G. Onorato, 2/3/2019).

Estos elementos, conjugados en la movilización estudiada, permitieron la visibilización de este sector social y sus organizaciones en el mapa social y político de la argentina a partir del 2016 . Entendiendo la capacidad de la festividad como nodo articulador de reivindicaciones populares, vemos lo religioso como un lugar político, donde confluyen demandas, conflictos y actores, atravesados por sentidos y memorias compartidas, y que otorgan a la marcha una potencia particular. Esa potencialidad como escenario de unidad contra las políticas de ajuste y de visibilización de un sector social en la agenda nacional ubicó la Marcha de San Cayetano como hecho político significativo durante el gobierno de Cambiemos y a la CTEP como un actor de relevancia en la política argentina de allí en adelante.

\section{FUENTES}

Entrevistas realizadas por el autor:

-Gildo Onorato, Secretario de Políticas Sociales del Movimiento Evita, integrante de la Mesa Nacional de la Confederación de los Trabajadores de la Economía Popular. Entrevista el 2/3/2019 en la ciudad de La Plata, Buenos Aires, Argentina.

-Rodrigo Bernales, referente del Movimiento de Trabajadores Excluidos Regional La Plata, Berisso y Ensenada. Entrevista el 31/1/2019 en la ciudad de La Plata, Buenos Aires, Argentina.

\section{Fuentes PERIODÍSTICAS}

Emilio Pérsico: "Las agrupaciones sociales no buscan desestabilizar". La Capital, 21/8/2016. Recuperado de https://www.lacapital.com.ar/politica/emilio-persico-las-agrupaciones-sociales-no-buscan-desestabilizar-n 1 212309.html 
“Diputados aprobó la declaración de Emergencia Social por tres años". La Nación, 7/12/2016. Recuperado de https://www.lanacion.com.ar/politica/diputados-aprobo-la-declaracion-de-la-emergencia-social-por-tres-a nos-nid 1962922

"El Senado convirtió en ley por unanimidad el proyecto de Emergencia Social". La Nación, 14/12/2016. Recuperado de https://www.lanacion.com.ar/politica/el-senado-convirtio-en-ley-por-unanimidad-el-proyecto-de-emergen cia-social-nid1966970

"Reencuentro de movimientos populares en Argentina por Tierra, Techo y Trabajo". En Movimientos Populares.org, 2015. Recuperado de https://movimientospopulares.org/2015/12/reencuentro-de-movimientos-populares-en -argentina-por-tierra-techo-y-trabajo/

“Nació la UTEP”. En ctepargentina.org, 21/12/2019. Recuperado de https://ctepargentina.org/nacio-la-utep/

"El titular del flamante gremio de la economía popular señaló como 'un logro' la unidad alcanzada". Agencia Télam, 23/12/2019. Recuperado de https://www.telam.com.ar/notas/201912/418632-el-titular-del-flamante-gremio -de-la-economia-popular-senalo-como-un-logro-la-unidad-alcanzada.html

"Nació la UTEP, el gremio de los trabajadores de la economía popular". Página 12, 22/12/2019. Recuperado de http s://www.pagina12.com.ar/237866-nacio-la-utep-el-gremio-de-los-trabajadores-de-la-economia-p

"Un encuentro entre trabajadores". Página 12, 25/9/16. Recuperado de https://www.pagina12.com.ar/diario/elpais /1-310221-2016-09-25.html

"Conferencia de prensa: Unidos por la justicia social”. En ctepargentina.org, 16/11/2016. Recuperado de https://cte pargentina.org/conferencia-prensa-unidos-la-justicia-social/

"Unidad por la justicia social: el reclamo del pueblo trabajador". Notas Periodismo Popular, 19/11/2016. Recuperado de https://notasperiodismopopular.com.ar/2016/11/19/unidad-por-la-justicia-social-el-reclamo-del-pueblo-t rabajador/

Esteban «Gringo» Castro: "Sólo la comunidad puede garantizar el futuro". Factor Francisco.org, 02/05/2020. Recuperado de http://www.factorfrancisco.org/esteban-gringo-castro-solo-la-comunidad-puede-garantizar-elfuturo/

\section{REFERENCIAS}

Abal Medina, P. (2017). Los movimientos obreros organizados de Argentina (2003- 2016). En Abal Medina, P., Natalucci, A. y Rosso, F., ¿Existe la clase obrera? (pp. 21-62). Buenos Aires: Capital Intelectual.

Bruno, D. (2016) Política y religión en el discurso de la CTEP. En Bruno, D. y Palumbo, M.M. (Eds.), Informe de medio término del Proyecto UBACYT Pedagogía, politica y acción colectiva. La dimensión político pedagógica de los movimientos populares urbanos en el AMBA. (pp. 102-114). Buenos Aires: UBA Sociales. Disponible en http:/ /www.isbn.org.ar/cal/laimg/6355/493629.pdf

Carbonelli M., Follari R., Esquivel J. C., Isuani A., Margari P., Ortiz G., Salinas L. y Vezzosi J. (2013). Religión y Política en la Argentina. En Mallimaci, F. (Dir.) Atlas de las creencias religiosas en la Argentina (pp.167-171). Buenos Aires: Biblos.

Carbonelli, M. y Giménez Beliveau, V. (2015). Militantes de Francisco: Religión y política en tiempos del Papa argentino. Nueva Sociedad, 260, 53-66. https://nuso.org/articulo/militantes-de-francisco/

Carbonelli, M. y Giménez Béliveau, V. (2016) Vidas militantes: trayectorias, saberes y éticas en el Movimiento Misioneros de Francisco". Revista de Ciencias Sociales, segunda época, 8(30), pp. 85-109.

Donatello, L. (2005) "La tensión entre las esferas religiosa y política en la Modernidad. Una lectura a través de Nietzsche y Weber”. Nómadas-Revista Crítica de Ciencias Sociales y Jurídicas. p. 1 - 17.

Donatello, L. (2006). Conflictividad política religiosa en la Argentina Moderna: Procesos de "teologización" de la política. Si somos americanos. Revista de Estudios Transfronterizos, 3(1), 83-104.

Dri, R. (comp.) (2003). Simbolos y Fetiches Religiosos en la construcción de la identidad popular. Buenos Aires: Editorial Biblos. 
Fernández Álvarez, M. I. (2016). Experiencias de precariedad, creación de derechos y producción colectiva de bienestar(es) desde la economía popular. Revista Ensambles, 4/5, 72-89.

Giménez Beliveau, V. y Carbonelli, M. (2017). Movilización política, memoria y simbología religiosa: San Cayetano y los movimientos sociales en Argentina. Revista latinoamericana de investigación crítica (CLACSO), 6, 51- 70.

Grabois, J. (2013) “Capitalismo de exclusión, periferias sociales y movimientos populares”. Scripta Varia (Pontifical Academy of Sciences), 123, 37-68.

Lenguita, P. A. (2017). Apuntes actuales del sindicalismo argentino. Revista de la Facultad de Ciencias Sociales (UBA), 93, 28-33.

Maldovan Bonelli J., Ynoub, E., Fernández Mouján, L. y Moler, E. (2017), Políticaspúblicas e instituciones de regulación socio-laboral para la Economia Popular. Supuestos y tensiones en el debate por la ley de Emergencia Social. Trabajo presentado en XIII Congreso Nacional de Estudios del Trabajo. El trabajo en conflicto: dinámicas y expresiones en el contexto actual. Asociación Argentina de Especialistas en Estudios del Trabajo, Buenos Aires. Recuperado a partir de: https://www.aset.org.ar/2017/ponencias/14_Maldovan.pdf

Mallimaci, F. (2000). Catolicismos en sectores populares ante el quiebre del estado de bienestar. Revista de Ciencias Sociales, 1, 115-130.

Mallimaci, F. (2013) Atlas de las creencias religiosas en la Argentina. Buenos Aires: Biblos.

Mallimaci, F.; Esquivel J.C. y Giménez Beliveau, V. (2009) Creencias religiosas y estructura social en Argentina del siglo XXI. Boletín de la BCN, 124, 75 - 100.

Marini, M. (2017). La movilización social y la transición democrática en la Argentina: la manifestación de San Cayetano de 1981. Trabajo presentado en XVI Jornadas Interescuelas Departamentos de Historia. Facultad de Humanidades, Universidad Nacional de Mar del Plata. Recuperado a partir de https://cdsa.aacademica.org/0 00-019/212.pdf

Melucci, A. (1999) Acción colectiva, vida cotidiana y democracia. Buenos Aires: CLACSO.

Merklen, D. (2005). Pobres ciudadanos. Las clases populares en la era democrática (Argentina, 1983-2003). Buenos Aires: Gorla.

Moreno, J. E. (2011). Discursos identitarios y articulación política en el campo popular argentino. Sociohistórica, 28, 13-39.

Moore, M. S. (2014) Pan y trabajo en cada coyuntura social: una aproximación a la semiosis religioso-política del culto a San Cayetano en Argentina. Trabajo presentado en I Jornadas de Religión y Política en América Latina y el Caribe y XII Jornadas interdisciplinarias a 25 años de los mártires de El Salvador. Universidad Católica de Córdoba. Recuperado a partir de http://pa.bibdigital.uccor.edu.ar/906/1/DC_Moore.pdf

Morris, M. B. (2014) ¿Un lugar para todos los compañeros?: Dinámica política y sindical de la Central de Trabajadores de la Argentina en los gobiernos kirchneristas (Tesis de grado, FaHCE-UNLP). Recuperado a partir de http:// www.memoria.fahce.unlp.edu.ar/tesis/te.978/te.978.pdf

Munck, G. (1995). Algunos problemas conceptuales en el estudio de los movimientos sociales. Revista Mexicana De Sociología, 57(3), 17-40.

Muñoz, M. A. (2018). Voluntades populares, voluntades laborales. Los gobiernos y la Confederación de los Trabajadores de la Economía Popular. Trabajo presentado en X Jornadas de Sociología de la Universidad Nacional de La Plata. Facultad de Humanidades y Ciencias de la Educación, Ensenada. Recuperado a partir de http://sedici.unlp.ed u.ar/handle/10915/79421

Muñoz, M. A. y Villar, L. (2017). Confederación de Trabajadores de la Economía Popular (CTEP en la CGT). Entre la organización sindical y el conflicto político-social (Argentina, 2011-2017). Crítica y Resistencias, revista de conflictos sociales latinoamericanos, 5, 22-52.

Natalucci, A. (2012). Los movimentistas. Expectativas y desafíos del Movimiento Evita en el espacio kirchnerista (2003-2010)". En Pérez, G. y Natalucci, A. (eds.), Vamos las bandas. Organizacionesy militancia kirchnerista (pp. 27-53). Buenos Aires: Trilce. 
Natalucci, A. y Morris, M. B. (2019). ¿Superando la fragmentación? Un análisis de las estrategias de articulación entre la CGT y la CTEP (2009-2017). Astrolabio, 23, 169-197. Recuperado a partir de https://revistas.unc.edu.ar/i ndex.php/astrolabio/article/view/23556

Palomino, H. (2005). Los sindicatos y los movimientos sociales emergentes del colapso neoliberal en Argentina. En de la Garza Toledo, E. (comp.). Sindicatos y nuevos movimientos sociales en América Latina (pp. 19-52). Buenos Aires: CLACSO.

Pérez, P. y López, E. (Coords). (2018). ¿Un nuevo ciclo regresivo en Argentina? Mundo del trabajo, conflictos laborales y crisis de hegemonía. La Plata: Universidad Nacional de La Plata. Facultad de Humanidades y Ciencias de la Educación.

Piva, A. (2018). Política económica y modo de acumulación en la Argentina de la posconvertibilidad. Revista Perfiles Latinoamericanos, 26(52). https://doi.org/10.18504/pl2652-006-2018

Retamozo, M. (2006). Los «piqueteros»: trabajo, subjetividad y acción colectiva en el Movimiento de Desocupados en Argentina. América Latina Hoy, 42, 109-128.

Retamozo, M. (2011) Movimientos sociales, política y hegemonía en Argentina. Revista Polis, 2(28), 243-279.

Salvia, A. (Coord.) (2017). Desarrollo Humano e Integración Social en la Argentina Urbana 2010-2016 (Documento estadístico). Observatorio de la Deuda Social Argentina. Universidad Católica Argentina. Disponible en: http: //bibliotecadigital.uca.edu.ar/repositorio/investigacion/desarrollo-humano-integracion-social-estadistico.pdf

Schuttenberg, M. (2012). La trayectoria política de Libres del Sur 2003-2011. Reconfiguración identitaria, alianza y ruptura con el kirchnerismo. En Pérez, G. y Natalucci, A. (eds.), Vamos las bandas. Organizaciones y militancia kirchnerista (pp.127-148). Buenos Aires: Nueva Trilce.

Svampa, M. (2005). Hacia el nuevo orden neoliberal. En: Autora, La sociedad excluyente.La Argentina bajo el signo del neoliberalismo (pp.21-49). Buenos Aires: Taurus.

Tilly, C. (1978). From Mobilization to Revolution. Estados Unidos: Michigan University.

Tóffoli, M. (2017). La CGT de los excluidos. La Confederación de Trabajadores de la Economía Popular (CTEP) (2011-2016). (Tesis de grado, FaHCE-UNLP). Recuperado a partir de http://www.memoria.fahce.unlp.edu.a $\mathrm{r} /$ tesis/te.1402/te.1402.pdf

Varela, P. (2017) La conflictividad laboral durante el primer año de Macri ¿Quién resiste? Revista de la Facultad de Ciencias Sociales / UBA, 93, 18-21.

Varesi, G. (2016). Tiempos de restauración: Balance y caracterización del gobierno de Macri en sus primeros meses. Realidad económica, 302, 6-34.

Vommaro, G. y Gené, M. (2017). Argentina: el año de Cambiemos. Revista de ciencia política, 37(2), 231-254.

Wainsztok, C.; Derqui, F. (2003). “La Religión como una forma de Racionalidad: el caso de San Cayetano.”. En Dri Ruben (comp.) (2003) Simbolos Y Fetiches Religiosos en la Construcción de la Identidad Popular. Buenos Aires: Editorial Biblos. pp.35-52

Zicari, J. (2016). "Las coaliciones neoliberales en la Argentina: los casos de la Alianza y Cambiemos". Realidad Económica, 307, 6-36.

\section{Notas}

1 El siguiente artículo recupera parte de los resultados obtenidos durante el proceso de investigación para la tesina de grado de la Licenciatura en Sociología de la Facultad de Humanidades y Ciencias de la Educación de la UNLP, denominada "Haciendo política entre santos y estampitas. La convivencia entre religiosidad popular y movilización política en la CTEP, a partir de la Marcha de San Cayetano por Paz, Pan, Tierra, Techo y Trabajo (7/8/2016)”.

2 Carolina Stanley fue, desde que la Alianza Cambiemos llegó al gobierno, la titular del Ministerio de Desarrollo Social de la Nación, a partir de 2017 llamado Ministerio de Salud y Desarrollo Social. Desde esta institución se administra gran parte de las políticas sociales que brinda el Estado.

3 Ver más en web oficial de CTEP Argentina: https://ctepargentina.org/nacio-la-utep/

4 Ver más en https://ctepargentina.org/conferencia-prensa-unidos-la-justicia-social/ 